\title{
Laparoscopic TME in rectal cancer - electronic supplementary: op-video
}

\author{
Alois Fürst • Oliver Schwandner • \\ Arthur Heiligensetzer • Igors Iesalnieks • Ayman Agha
}

Received: 22 August 2009 / Accepted: 16 September 2009/Published online: 15 January 2010

(C) The Author(s) 2010. This article is published with open access at Springerlink.com

\begin{abstract}
Background Laparoscopic total mesorectal excision (TME) for rectal cancer has been proved in various studies. The minimal invasive procedure is feasible and safe which was demonstrated in many studies. However, the results of prospective, randomized studies providing valuable evidence are still not available. Compared to conventional surgery, the laparoscopic technique has short-term advantages including less pain, shorter duration of postoperative ileus, less fatigue, better pulmonary function, and less blood loss (Leung et al., Lancet 363:1187-1192, 2004; Braga et al., Dis Colon Rectum 48:217-223, 2005; Jayne et al., J Clin Oncol 25:3061-3068, 2007; Agha et al., Surg Endosc 22:2229-2237, 2008).

Methods The autonomic nerve sparing TME technique is the gold standard in rectal cancer resection even in conventional or laparoscopic procedure. With regard of the oncological dimension, the laparoscopic TME technique is not different compared to the open procedure. However, a standardized laparoscopic step-by-step procedure may simplify the operation and can reduce operation time.

Results There are no studies available which compare different types of TME procedures. Most surgeons start the operation left laterally mobilizing the sigmoid colon first. In the laparoscopic technique, we recommend the medial to
\end{abstract}

Electronic supplementary material The online version of this article (doi:10.1007/s00423-009-0556-y) contains supplementary material, which is available to authorized users.

\footnotetext{
A. Fürst $(\square) \cdot$ O. Schwandner $\cdot$ A. Heiligensetzer

Department of Surgery and Minimal Invasive Surgery,

Caritas-Clinic St. Josef,

Landshuterstr. 65,

93053 Regensburg, Germany

e-mail: afuerst@caritasstjosef.de

I. Iesalnieks $\cdot$ A. Agha

Department of Surgery, University Clinic Regensburg,

Franz Josef Strauss Allee,

93042 Regensburg, Germany
}

lateral approach starting the operation at the right side of the rectum and sigmoid colon. A nerve sparing TME technique can be performed easier, and the identification of the left ureter may be simplified. After multiple workshops and extensive discussion with national and international experts, we developed a standardized laparoscopic " 10 step TME procedure." Reviewing the results of laparoscopic TME the studies do not allow firm conclusions as to the questions of whether the safety and efficacy of laparoscopic TME is equal or superior to open TME (Breukink et al. 2006). Actually, we are waiting for large prospective randomized studies comparing laparoscopic TME with the traditional open procedure (Bonjer et al., Dan Med Bull 56:89-91, 2009).

Conclusion Laparoscopic TME appears to have clinically measurable short-term advantages in patients with primary resectable rectal cancer based on evidence mainly from nonrandomized studies (Breukink et al. 5). In nearly all published studies, the efficacy and technical feasibility of laparoscopic surgery for rectal cancer could be demonstrated regarding perioperative morbidity and oncological outcome. A standardized laparoscopic TME technique can be strongly recommended.

Keywords Laparoscopic rectal resection - Laparoscopic TME $\cdot$ Rectal cancer $\cdot$ Operation technique $\cdot$ Oncological outcome Video rectal resection

\section{Introduction}

Laparoscopic total mesorectal excision (TME) is technically feasible and safe; however, the oncological outcome has not been evaluated by large studies with high evidence level to date [7-13]. Large prospective randomized studies comparing laparoscopic-assisted with the conventional TME are not available. Actually, well-documented prospective patient series represents an important contribution to the evaluation 


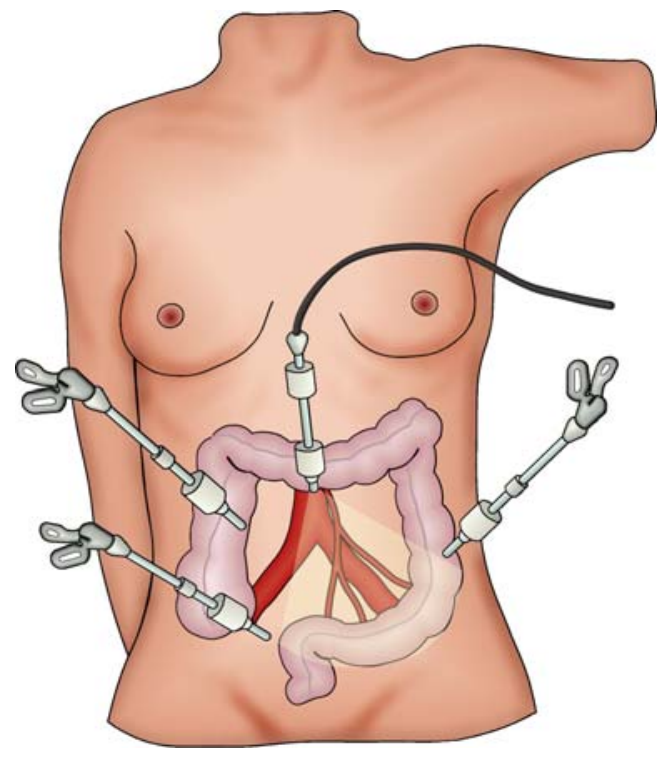

Fig. 1 Trocar position of laparoscopic rectal cancer surgery

of surgery adopting the laparoscopic-assisted technique. For colorectal carcinoma, advantages of the minimally invasive surgery have been indicated by several studies [11, 14, 15]. Multicenter prospective randomized studies have shown comparable postoperative morbidity and oncological outcomes for colon carcinoma [16-18].

\section{Standardized surgical technique of laparoscopic TME}

\section{Position of the patient (Video 1)}

The positioning of the patient is essential in laparoscopic TME. The patient is positioned in the perineal lithotomy position. The operating table must have enough mobility to facilitate a head down and rightsided position simultaneously.

\section{Trocar position}

An open access of the first trocar is recommended. The position of the camera trocar is $2 \mathrm{~cm}$ above the umbilicus.
Two trocars are localized at the lower part of the abdomen and one trocar at the right middle part (Fig. 1). A fifth trocar is optional.

3. Ten-step procedure of laparoscopic TME (*Video 2)

A standardized laparoscopic procedure helps to make the operation easier and faster. Especially the "medial to lateral approach" helps to keep the autonomic nerves intact and simplifies the mobilization of the left colon and the identification of the left ureter (Table 1).

\section{Colonic pouch}

A short 5-cm-long colonic J-pouch is recommended as shown by an international prospective randomized study [19].

5. Protective ileostomy

According to the guidelines, a protective ileostomy is recommended after TME in almost all countries.

*Video clips of several patients

\section{Conclusion}

Laparoscopic TME for rectal cancer is still a matter of controversial discussions. One important question is whether laparoscopic surgery achieves the oncological quality criteria of conventional rectal surgery. The results of retrospective and prospective studies published to date on rectal cancer suggest that minimally invasive surgery is able to maintain the recommended oncological standards of conventional tumor surgery, and that morbidity and mortality do not differ significantly from open surgery. However, few centers are able to present larger numbers of laparoscopically treated patients with rectal cancer. At present, there are only shortterm results available, without significant differences found between the laparoscopic and the open resection [1, 2, 4, 7-9, 12, 14, 20-24]. Thus, more studies with high patient
Table 1 Standardized ten-step procedure of laparoscopic TME

\begin{tabular}{ll}
\hline 1 & Medial to lateral preparation of arteria rectalis superior and autonomic nerves \\
2 & Identification of the left ureter \\
3 & Clip the arteria mesenterica inferior \\
4 & Clip the vena mesenterica inferior \\
5 & Mobilization of the left colon (medial and lateral) \\
6 & Mobilization of the left flecture (medial/lateral/omental) \\
7 & Preparation along the mesorectal plane \\
8 & Division of the distal rectum (endostapler) \\
9 & Extra-abdominal division of the descending colon \\
10 & Anastomosis with a transanal stapler device \\
\hline
\end{tabular}


numbers and long-term follow-up are needed to compare patient outcome and long-term survival rates after open or laparoscopic surgery (color II trial in progress) [6].

Open Access This article is distributed under the terms of the Creative Commons Attribution Noncommercial License which permits any noncommercial use, distribution, and reproduction in any medium, provided the original author(s) and source are credited.

\section{References}

1. Leung KL, Kwok SP, Lam SC, Lee JF, Yiu RY, Ng SS, Lai PB, Lau WY (2004) Laparoscopic resection of rectosigmoid carcinoma: prospective randomized trial. Lancet 363:1187-1192

2. Braga M, Frasson M, Vignali A, Zuliani W, Civelli V, Di Carlo V (2005) Laparoscopic versus open colectomy in cancer patients: long-term complications, quality of life, and survival. Dis Colon Rectum 48:217-223

3. Jayne DG, Guillou PJ, Thorpe H, Quirke P, Copeland J, Smith A, Heath RM, Brown J (2007) Randomized trial of laparoscopicassisted resection of colorectal carcinoma: 3-year results of the UK MRC CLASSIC Trial Group. J Clin Oncol 25:3061-3068

4. Agha A, Fürst A, Hierl J, Iesalnieks I, Glockzin G, Anthuber M, Jauch KW, Schlitt H (2008) Laparoscopic surgery for rectal cancer-oncological results and clinical outcome of 225 patients. Surg Endosc 22:2229-2237

5. Breukink S, Pierie J, Wiggers T (2006) Laparoscopic versus open total mesorectal excision for rectal cancer (Review). Cochrane Database of Systematic Reviews, Issue 4. Art. No.:CD005200

6. Bonjer HJ, Cuesta MA, Lacy AM, Haglind E, Fürst A, Lange JF, Hoop WCJ, Buunen M (2009) COLOR II. A randomized clinical trial comparing laparoscopic and open surgery for rectal cancer. Dan Med Bull 56:89-91

7. Anthuber M, Fürst A, Elser F et al (2003) Outcome of laparoscopic surgery for rectal cancer in 101 patients. Dis Colon Rectum 46:10471053

8. Bärlehner E, Benhidjeb T, Anders S et al (2005) Aktueller Stand der laparoskopischen Rektumresektion beim Karzinom. Chir Gastroenterol 21:54-61

9. Feliciotti F, Guerrieri M, Paganini M et al (2003) Long-term results of laparoscopic vs. open resections for rectal cancer for 124 unselected patients. Surg Endosc 17:1530-1535

10. Leroy J, Jamali F, Forbes L et al (2003) Laparoscopic total mesorectal excision (TME) for rectal cancer surgery: long-term outcomes. Surg Endosc 2:281-289

11. Milsom JW, Böhm B, Hammerhofer KA et al (1998) A prospective, randomized trial comparing laparoscopic versus conventional techniques in colorectal cancer surgery: a preliminary report. Am Coll Surg 187:46-57
12. Morino M, Parini U, Giraudo G et al (2003) Laparoscopic total mesorectal excision. A consecutive series of 100 patients. Ann Surg 237:335-342

13. Tang CL, Eu KW, Tai BC et al (2001) Randomized clinical trial of the effect of open versus laparoscopically assisted colectomy on systemic immunity in patients with colorectal cancer. Br J Surg 88:801-807

14. Abraham NS, Young JM, Solomon MJ (2004) Meta-analysis of short-term outcomes after laparoscopic resection for colorectal cancer. Br J Surg 91:1111-1124

15. Bruch HP, Esnaashari H, Schwandner O (2005) Current status of laparoscopic therapy of colorectal cancer. Dig Dis 23:127134

16. Buunen M, Veldkamp R, Hop WC, Kuhry E, Jeekel J, Haglind E, Påhlman L, Cuesta MA, Msika S, Morino M, Lacy A, Bonjer HJ, Colon Cancer Laparoscopic or Open Resection Study Group (2009) Survival after laparoscopic surgery versus open surgery for colon cancer: long-term outcome of a randomised clinical trial. Lancet Oncol 10:44-52

17. Jayne DG, Guillou PJ, Thorpe H, Quirke P, Copeland J, Smith AM, Heath RM, Brown JM, UK MRC CLASICC Trial Group (2007) Randomized trial of laparoscopic-assisted resection of colorectal carcinoma: 3-year results of the UK MRC CLASICC Trial Group. J Clin Oncol 25:3061-3068

18. Clinical Outcomes of Surgical Therapy Study Group (2004) A comparison of laparoscopically assisted and open colectomy for colon cancer. N Engl J Med 350:2050-2059

19. Fazio VW, Zutshi M, Remzi FH, Parc Y, Ruppert R, Fürst A, Celebrezze J Jr, Galanduik S, Orangio G, Hyman N, Bokey L, Tiret E, Kirchdorfer B, Medich D, Tietze M, Hull T, Hammel J (2007) A randomized multicenter trial to compare long-term functional outcome, quality of life, and complications of surgical procedures for low rectal cancers. Ann Surg 246:481-490

20. Fleshman J, Wexner S, Anvari M et al (1999) Laparoscopic vs. open abdominoperineal resection for cancer. Dis Colon Rectum 42:930-939

21. Guillou PJ, Quirke P, Thorpe H et al (2005) Short term endpoints of conventional versus laparoscopic assisted surgery in patients with colorectal cancer (MRC CLASSIC trail): multicentre, randomized controlled trail. Lancet 365:1718-1726

22. Lacy AM, Garcia-Valdecasa JC, Delgado S et al (2002) Laparoscopy-assisted colectomy versus open colectomy for treatment of non-metastatic colon cancer: a randomised trial. Lancet 359:2224-2229

23. Lezoche E, Guerrieri M, De Sanctis A et al (2006) Long-term results of laparoscopic versus open colorectal resections for cancer in 235 patients with a minimum follow-up of 5 years. Surg Endosc 20:546-553

24. Sauer R, Becker H, Hohenberger W et al (2004) Preoperative versus postoperative chemoradiotherapy for rectal cancer. N Engl J Med 351:1731-1740 